Proc. Indian Acad. Sci. (Chem. Sci.), Vol. 90, Number 2, April 1981, pp. 83-88. (C) Printod in India.

\title{
Infrared absorption spectra of As-Se glasses
}

\author{
R MOHAN and $\mathrm{K} J$ RAO* \\ Solid State and Structural Chemistry Unit, Indian Institute of Science, \\ Bangalore 560012 , India
}

MS received 14 October 1980

\begin{abstract}
IR absorption spectra of As-Se glasses have been studied over a wide range of compositions. Various two-phonon, multiphonon (cumbination tones) and impurity absorptions have been identified. Compositional variation of relative band intensities has been explained in terms of the chemically ordered network model.
\end{abstract}

Keywords. Infrared spectra; As-Se glasses.

\section{Introduction}

Infrared spectroscopy of chalcogenide glasses has attracted wide attention because of their special IR transmitting properties. In particular, $\mathrm{As}_{2} \mathrm{Se}_{3}$ glass has been studied in detail by many workers (Edmond and Redfearn 1963; Hilton et al 1966; Taylor et al 1970; Lucovsky 1972; Moynihan et al 1975). Recently Moynihan et al (1975) have reported the IR spectra of glassy $\mathrm{As}_{2} \mathrm{Se}_{3}$ doped with $\mathrm{As}_{2} \mathrm{O}_{3}$ in the region 250 to $4000 \mathrm{~cm}^{-1}$. Spectra of amorphous As (Lucovsky and Knight 1974 ; Greaves et al 1979), Se (Hilton et al 1966; Savage and Nielsen 1964 ; Lucovsky et al 1967; Siemsen and Riccius 1969) and As-Se (Hilton et al 1966; Moynihan et al 1975) have also been reported in the literature and absorption frequencies of a morphous As, $\mathrm{Se}, \mathrm{As}-\mathrm{Se}$ and $\mathrm{As}_{2} \mathrm{Se}_{3}$ below $500 \mathrm{~cm}^{-1}$ are summarised in table 1. Molecular vibration calculations have been performed by Lucovsky (1972) and Lucovsky and Martin (1972) who find that the spectrum of $\mathrm{As}_{2} \mathrm{Se}_{3}$ conform; to that of vibrating $\mathrm{AsSe}_{3}$ units. In the 200 to $1200 \mathrm{~cm}^{-1}$ region $\mathrm{As}_{2} \mathrm{Se}_{3}$ exhibits several peaks due to multiphonon absorption (Moynihan et al 1975). Some of the rather intense absorption bands appear to be due to the presence of $\mathrm{As}_{2} \mathrm{O}_{3}$ and $\mathrm{SeO}_{2}$ impurities. $\mathrm{As}_{2} \mathrm{O}_{3}$ having a very high extinction coefficient (Hilton et al 1966; Moynihan et al 1975; Jerger and Sherwood 1964) gives rise to bands even at low concentrations of $\sim 100 \mathrm{ppm}$ (below the saturation solubility of $\mathrm{As}_{2} \mathrm{O}_{3}$ in $\mathrm{As}_{2} \mathrm{Se}_{3}$ ).

Various properties of binary As-Se glasses have been investigated in this laboratory (Mohan et al 1980; Rao and Mohan 1980) and the properties support a

* To whom all correspondence should be made. 